\title{
Cytokeratins of the Stratum Medium and Stratum Internum of the Equine Hoof Wall in Acute Laminitis
}

\author{
By $O$. Wattle
}

Department of Large Animal Clinical Sciences, Faculty of Veterinary Medicine, Swedish University of Agricultural Sciences, Uppsala, Sweden.

\begin{abstract}
Wattle O: Cytokeratins of the stratum medium and stratum internum of the equine hoff wall in acute laminitis. Acta vet. scand. 2000, 41, 363-379. - The cytoskeleton of living keratinocytes consists mainly of cytokeratins that have polymerised into intermediate filaments. The aim of this study was to describe the expression of cytokeratins in the living epidermal cells of the weight-bearing parts of the equine hoof wall during acute spontaneous laminitis. A total of 9 hooves from 3 horses subjected to euthanasia within $48 \mathrm{~h}$ of the first clinical signs of laminitis were sectioned and examined. The cytokeratins in the stratum medium and stratum internum of the hoof wall were characterized by 1- and 2-dimensional gel electrophoresis, and the tissue distribution of the cytokeratins was studied by immunohistochemical staining. The biochemical results showed the same set of cytokeratins as was seen in 8 normal horses, reported on previously, used as controls. The immunohistochemical results indicated a difference between normal horses and horses with acute laminitis in the content of cytokeratins in the basal cells of the matrix of the stratum medium of the hoof wall and in the basal and suprabasal cells in the stratum internum at the mid level of the hoof wall. However, no conclusion could be drawn as to whether this change in the cytokeratin distribution in laminitis was primary or was caused by the initiation of the local tissue-repairing process.
\end{abstract}

electrophoresis; immunohistochemistry.

\section{Introduction}

Laminitis is a common cause of lameness in the horse. This condition causes damage to the laminar region of the hoof, and in severe cases the terminal result may be a permanent displacement of the third phalanx, the dermal laminae and the deepest layer of the epidermis. Over the years, a number of different theories concerning the aetiology and pathogenesis of equine laminitis have been put forward (Hood 1999). The present theories predominating in the literature are that it is caused by a primary disturbance of the blood circulation within the hoof followed by ischaemia in the laminar region (Coffman et al. 1970, Weiss 1997), or by a primary disturbance of the lamellar basement membrane caused by metalloproteinases (Pollitt 1996, Johnson et al. 1998, Pollitt \& Daradka 1998). However, the aetiology and pathogenesis are still obscure.

Obel (1948) proposed a different concept of the pathogenesis of equine laminitis. He observed that the primary morphological change, which occurs in the early stage of acute laminitis, appears in the epidermis and consists of disappearance of the onychogenic acidophilic fibrillar structures, which, according to Obel, are normally present in the suprabasal cells of the secondary epidermal laminae and in the zone of cornification of the matrix of the stratum medium of the hoof wall. He also detected a 
change in appearance of the zone of cornification of the periople and chestnut. Obel believed that the disappearance of the acidophilic fibrils in the laminar layer leads to a reduction in the tenacity of the secondary epidermal laminae (SEL), which in turn causes overstretching of the SEL. On the basis of these findings and his histopathological observation that there were no morphological changes in the corium within the first $6 \mathrm{~h}$ after the onset of lameness, Obel (1948) proposed that the pathological changes in laminitis are a result of a primary disturbance of the metabolism of the keratinising epidermal cells. Furthermore, the changes in the lamellar corium were considered to be secondary to the deformation of the epidermal laminae. This primary metabolic disturbance has been thought to delay the differentiation of the epithelial cells and thereby alter the fibrillar structures within the keratinocytes (Obel 1948, Ekfalck 1991). Linford (1987) found corresponding morphological changes among horses with experimentally induced laminitis, and in subclinical cases among such horses he observed lamellar elongation without oedema or lamellar necrosis.

The cytoskeleton of the living keratinocytes of the hoof wall is mainly composed of cytokeratins that have polymerised into intermediate filaments (Baden \& Kvedar 1991). A web of these filaments extends across the cell from the nuclear envelope in the centre of the cell to the desmosomes and hemidesmosomes at the cell periphery (Fuchs 1995, Fuchs 1997). These intermediate filaments are included in the acidophilic fibrils described by Obel (1948).

The cytokeratins are divided into 2 types, acidic and basic, according to their isoelectric point (pI). In the normal equine hoof wall, the molecular weight $\left(\mathrm{M}_{\mathrm{r}}\right)$ of the basic keratins ( $\mathrm{pI}>5.6$ ) ranges from about 59 to $71 \mathrm{kDa}$, and that of the acidic keratins $(\mathrm{pI}<5.6)$ from about 47 to 65 $\mathrm{kDa}$ (Wattle 1998).

The aim of the current study was to investigate by biochemical and immunohistochemical analysis, the cellular expression of cytokeratins in the stratum medium and stratum internum of the hoof wall in hooves showing various degrees of morphological changes, from horses with acute spontaneous laminitis, and in this way to test Obels`s hypothesis that the primary disturbance in laminitis alters the fibrillar structure within the keratinocyte.

\section{Materials and methods}

\section{Horses}

Tissue samples were obtained from the hooves of 3 horses suffering from acute laminitis.

The criteria for inclusion of a horse in the study were

1) clinical signs of acute laminitis, 2) the owner's desire to stop treatment within $48 \mathrm{~h}$ of the first clinical signs of laminitis, 3) no previous clinical signs of laminitis, and 4) the owner's consent to the hooves being used for analysis.

The grades of signs of lameness as proposed by Obel (1948) were used in this study.

1. In a standing position, the horse lifts its feet incessantly, often at intervals of but a few seconds ("paddling"). At a walking pace it does not show any lameness but the trotting gait is short and stilty.

2. The horse moves quite willingly at a walking pace but the gait is characteristic for laminitis. A forefoot may be lifted without difficulty.

3. The horse moves most reluctantly and vigorously resists attempts to lift a forefoot.

4. At this stage, the horse does not move without being forced to.

Horse 1. Ardennes mare, 16 years old, gave birth to a foal on 25 April and suffered from metritis due to a retained placenta. She was treated with oxytocin, Flunixin meglumine, and penicillin. The mare started to show signs of 

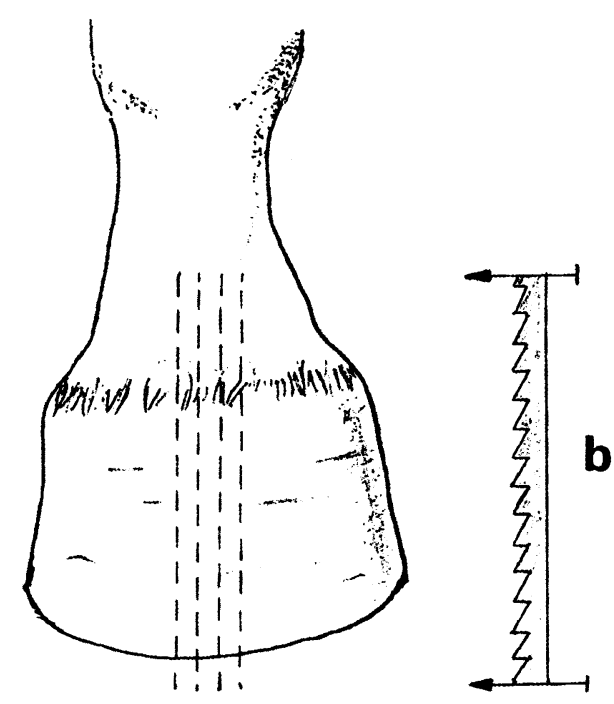

a

Figure 1 a: Using an electric band-saw, four sagittal incisions, $5 \mathrm{~mm}$ apart, were made through the hoof wall (a). Together with the four sagittal incisions a vertical saw cut in a lateral to medial direction (b) produced three 5 - $\mathrm{mm}$ - wide slices. These slices, containing the stratum externum, stratum medium and stratum internum of the hoof were dissected free of the underlying structures with a scalpel blade.

laminitis of grade 1-2 on 26 April. On 27 April, the signs increased to Obel grade 3 . She was euthanised with an overdose of pentobarbital within $30 \mathrm{~h}$ of the time she was last seen walking with a normal gait (i.e., she had signs of lameness for between 24 and $30 \mathrm{~h}$ ). The horse was mostly lying down during its last $14 \mathrm{~h}$. Samples were taken from all 4 hooves.

Horse 2. Swedish warmblood mare, 14 years old, had been treated with Flunixin meglumine, penicillin and a fomenting bandage for 4 days (23-26 June) because of a minor wound and lymphangitis in a hind limb. The horse had also been turned out on a new pasture for the previous 4 days. In the morning of 27 June, the hind limb was not swollen, the gait was normal, and

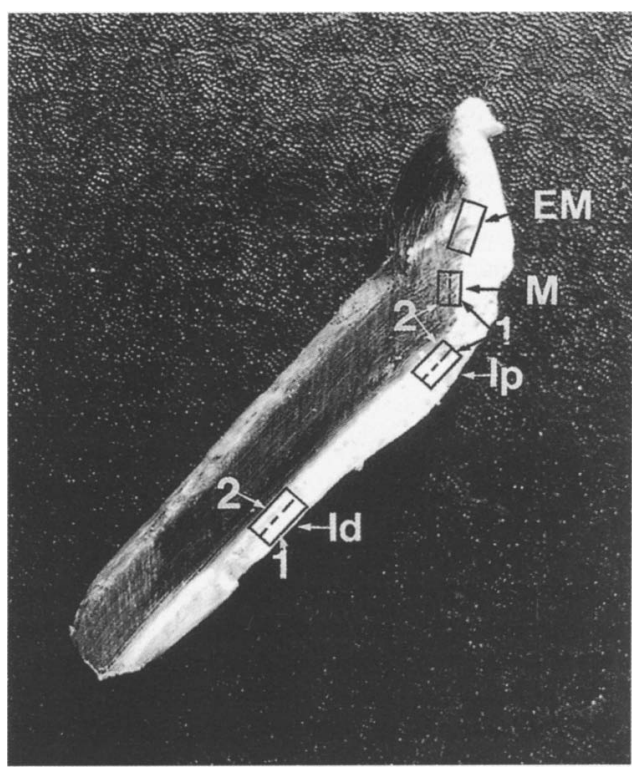

Figure 1b: From each slice, four tissue blocks (EM, M, Ip and Id) were taken.

EM. Matrix of the periople and the most dorsal part of the matrix of the stratum medium

M. Matrix of the stratum medium.

Ip. The most proximal part of the stratum internum and about $1 \mathrm{~mm}$ of the interior part of the stratum medium.

Id. Stratum internum and about $1 \mathrm{~mm}$ of the stratum medium at the mid level of the hoof.

Tissue blocks for electrophoresis were cut to make one inner (1) and one outer (2) half.

the body temperature was $37.6^{\circ} \mathrm{C}$. When the horse was brought in from the pasture in the evening of 27 June, she showed signs of laminitis grade 3 , and the body temperature was $39.7^{\circ} \mathrm{C}$. Before euthanasia by captive bolt and exsanguination in the morning of 28 June, the mare showed signs of Obel grade 4 laminitis, a heart rate of $85 / \mathrm{min}$ and extensive perspiration, and had dry feces. At the time of euthanasia, she had shown signs of lameness for between 14 and $24 \mathrm{~h}$. Samples were taken from all 4 hooves. 
Table 1. Antibodies used for immunohistochemical staining.

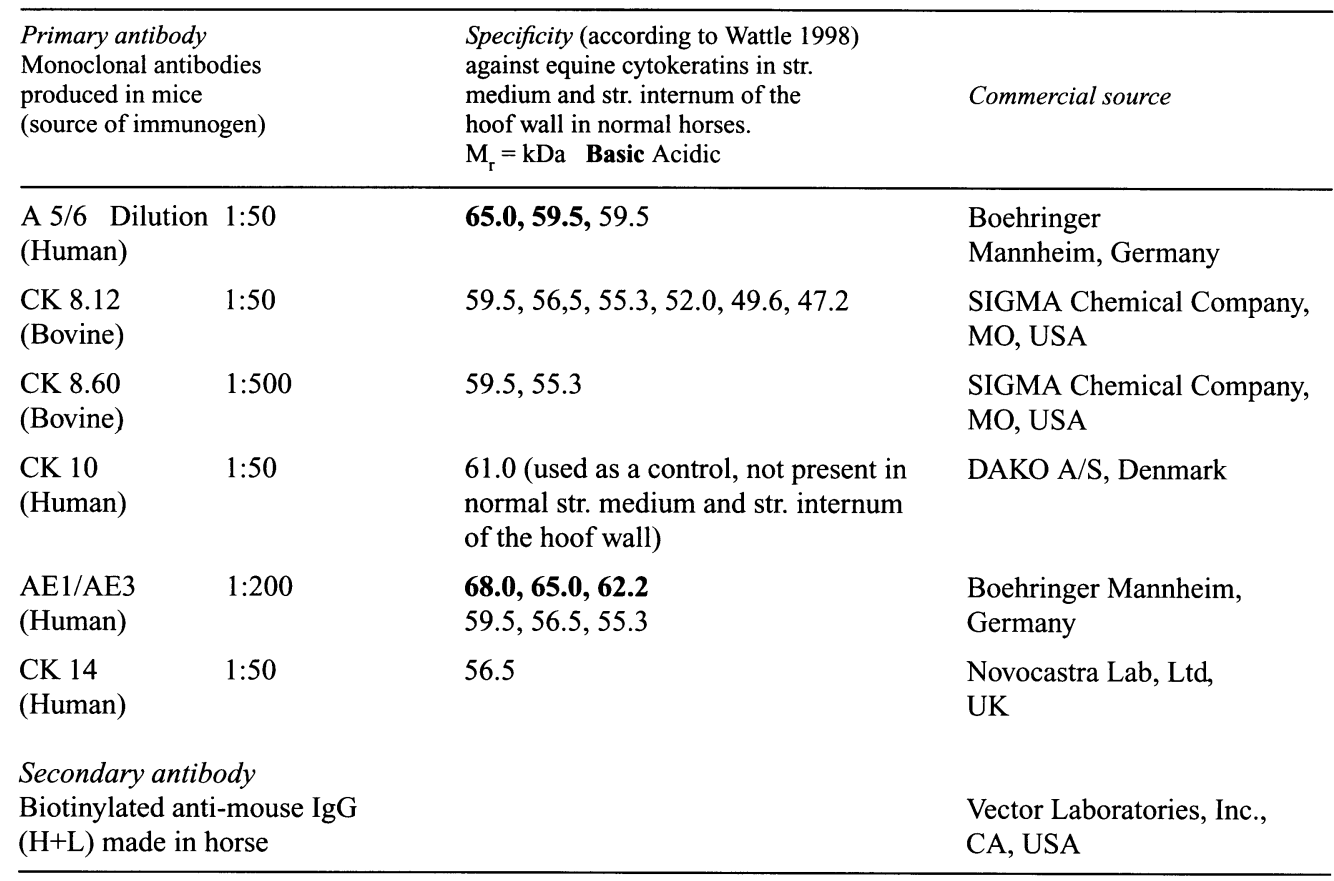

Horse 3. Norwegian Fjord mare, 12 years old. On 10 June, she was found in the pasture with signs of laminitis of grade 2-3. The mare was given Flunixin meglumine intravenously and mineral oil by a nasogastric tube. Within $48 \mathrm{~h}$, the signs had increased to grade 4 , and the horse was euthanised with an overdose of pentobarbital. Samples were taken from one front hoof only, in accordance with the owner's wish.

The methods used have been described in detail previously by Wattle (1998) and will only be summarized briefly below.

\section{Preparation of tissue fragments}

Following euthanasia, the feet were disarticulated at the fetlock joint and then sampled as shown in Figs. 1a and b. The part of the tissue block designated EM (see Fig. 1b) that was composed of stratum externum (i.e. the periople) was not evaluated in the present work.

The specimens were obtained immediately after euthanasia and stored on ice for no longer than $1.5 \mathrm{~h}$ before final fixation. Samples for biochemical studies (i.e. tissue samples from one front hoof of each horse) were frozen at $-80^{\circ} \mathrm{C}$ and then stored at $-30{ }^{\circ} \mathrm{C}$ until needed. Samples for immunohistochemistry were fixed in 5\% buffered formaldehyde ( $\mathrm{pH}$ 7.2) (in cases of cryostat sectioning for immunohistochemistry, small tissue samples were frozen in liquid nitrogen and stored at $-80^{\circ} \mathrm{C}$ ). To avoid post mortem artifacts, such as post-mortem stretching or separations between cell layers, all tissue samples for histological examination were very carefully handled until they were embedded or frozen. 
Criteria for classification of polypeptides as cytokeratin

The criteria employed included the polypeptide's solubility in the extraction buffers used, the electrophoretic pattern, and the reactivity with antibodies against cytokeratins. The antibodies used were chosen on the basis of their specificity against equine cytokeratins (Wattle 1998). Details of the monoclonal antibodies (Mabs) used are given in Table 1.

\section{Biochemistry}

Equipment and electrophoretic gels were purchased from Pharmacia (Pharmacia Biotech AB, Uppsala, Sweden). The chemicals used were of analytical grade and were purchased from Sigma (Sigma Chemical Company, St. Louis, MO, USA) or Merck (Merck, Darmstadt, Germany), unless otherwise stated.

\section{Keratin extraction}

Using a dissecting microscope (magnification, $15-40 \times)$, most of the corium was removed from the frozen sample with a scalpel blade. Each sample was washed twice with ethanol, cut to make one inner and one outer half (Fig. 1b), minced with a scalpel blade, and extracted (Wattle 1998). The extracts were stored at room temperature or at $-30^{\circ} \mathrm{C}$ until they were to be subjected to electrophoresis. In earlier experiments, freezing of the extracts was found to affect the isoelectric point of the protein (Wattle 1998), therefore, freezing of the extracts was avoided when they were to be analysed 2-dimensionally.

\section{One- (1-D) and 2-dimensional (2-D) gel electrophoresis}

The above-mentioned extracts were analysed by 1-D and 2-D gel electrophoresis as described by Wattle (1998). The proteins were visualised by silver staining. The molecular weight was determined by scanning samples and low-mo- lecular-weight marker proteins (LMW Electrophoresis Calibration Kit, Pharmacia Biotech AB, Uppsala Sweden) with an Ultroscan XL laser densitometer using GelScan XL 2.0 software for evaluation. The estimated error in $M_{r}$ was $\pm 1 \mathrm{kDa}$. Estimation of isoelectric points was based on the position of the spots along the linear $\mathrm{pH}$ gradient generated in the first dimension. The estimated error in $\mathrm{pI}$ values was \pm 0.2 . Since the number and position of proteins were the same as those in the control horses, within the molecular-weight range for cytokeratins on the electrophoretic gels, immunoblotting was not performed on samples from stratum medium and stratum internum of the laminitic horses.

\section{Immunohistochemistry}

Formalin-fixed tissues were dehydrated and embedded in paraffin by automatic tissue processing (Citadell 1000, Shandon Scientific Ltd, Runcom, Cheshire, UK) within 48 h of euthanasia. For evaluation of the morphology of the material, sections $5 \mu$ m thick from all samples were stained with Mayer's haematoxylin and eosin (H \& E) and then examined.

The avidin-biotin-peroxidase complex (ABC) procedure (Vectastain Elite ABC kit, Vector Laboratories, Burlingame, CA, USA) (Hsu et al. 1981) was used for the immunohistochemical study as described by Wattle (1998). Sections $5 \mu \mathrm{m}$ thick were cut from paraffin blocks and placed on polylysine-coated slides. The slides were placed in plastic slide racks containing distilled water and heated in a $750 \mathrm{~W}$ microwave oven for $3 \times 3 \mathrm{~min}$ for antigen unmasking, to increase the antibody reactivity (Cattoretti et al. 1993, Hazelbag et al. 1995). Negative control staining was performed by replacing the primary antibody with Tris-buffered saline (TBS) buffer and by using the CK $10 \mathrm{Mab}$. The CK 10 Mab reacts with a cytokeratin that is not present in the strata medium and internum of 

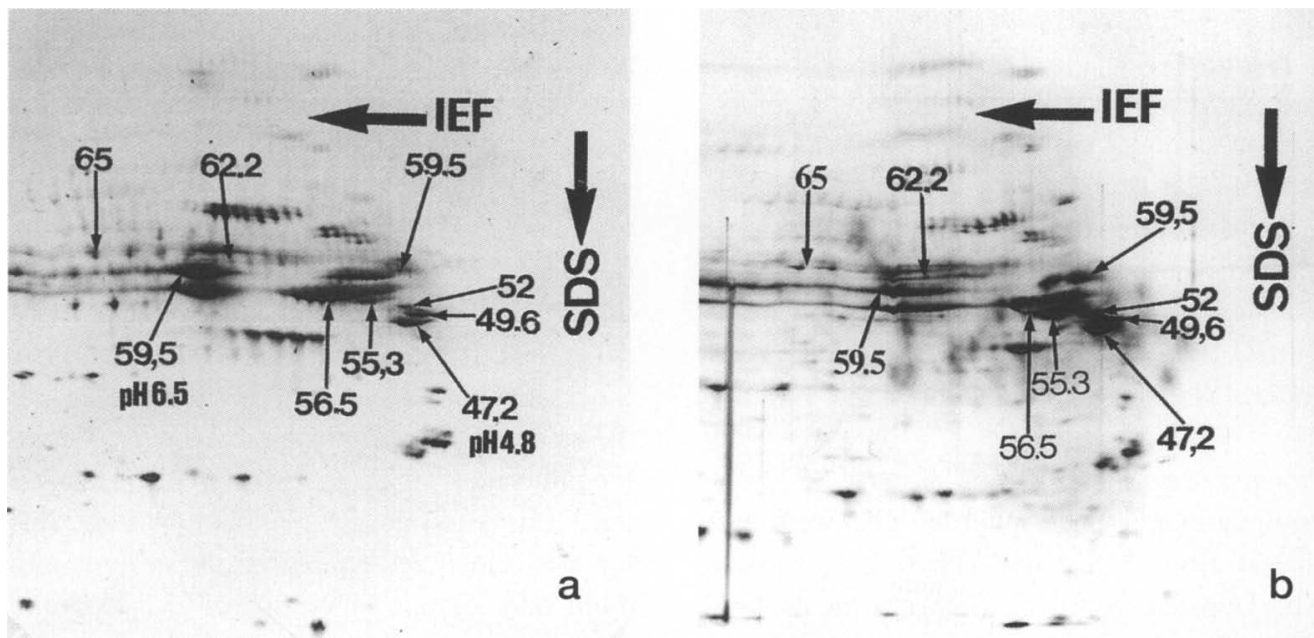

Figure 2: Silver-stained proteins from the laminar layer separated by 2-D electrophoresis. The horizontal arrow indicates the direction of the first dimension (separation according to isoelectric points, IEF), with basic proteins on the left and acidic proteins on the right. The vertical arrow indicates the second dimension (separation according to molecular weight in the presence of SDS). Average molecular weights $(\mathrm{kDa})$ are given for some of the polypeptides.

a) Typical result from samples of the laminar layer at the Id2 position in the control horses.

b) Laminitic horse 3. Laminar layer at the Id2 position.

normal horses (Wattle 1998). Normal control tissues were run side-by-side with tissues from the laminitic animals. Sections were examined under a light microscope for estimation of the location and amount of brown reaction product. To test for antibody binding to the epitope not affected by formaldehyde, cryostat sections corresponding to the paraffin-embedded tissue samples were obtained. For evaluation of the specific staining reaction, a grading system for the intensity of staining was used: - negative; $(+)$ possible staining, i.e. slight and inhomogeneous; + slight and homogeneous; ++ moderately; and +++ strongly positive. Photomicrographs were taken, using a Zeiss Axioplan microscope with an MC 100 spot microscope camera and a $35 \mathrm{~mm}$ film cassette with Fuji, 100 ASA, 35-mm film for colour prints. All sections were photographed through blue and grey filters.

Table 2. Silver-stained proteins classified as cytokeratins in extracts from stratum medium and stratum internum of horses with acute laminitis.

\begin{tabular}{lcccccccccc}
\hline & \multicolumn{3}{c}{ Basic Mr $(\mathrm{kDa})$} \\
\hline Str. medium & $\mathbf{6 8}$ & $\mathbf{6 5}$ & $\mathbf{6 2 . 2}$ & $\mathbf{5 9 . 5}$ & 59.5 & 56.5 & 55.3 & 52 & 49.6 & 47.2 \\
Str. internum & & $\mathbf{6 5}$ & $\mathbf{6 2 . 2}$ & $\mathbf{5 9 . 5}$ & 59.5 & 56.5 & 55.3 & 52 & 49.6 & 47.2 \\
\hline
\end{tabular}

These results did not differ from those in the control horses. For relative amounts of proteins in the control horses, see Wattle (1998). 


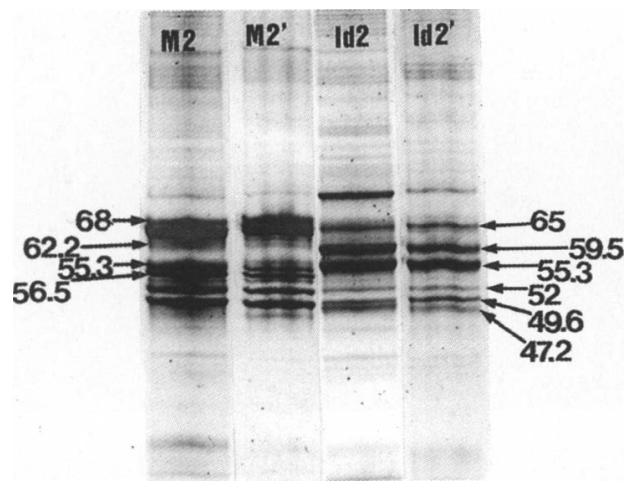

Figure 3: Silver-stained proteins from the stratum medium and stratum internum separated by $1-D$ electrophoresis in a $12.5 \%$ polyacrylamide homogeneous gel. M2 and Id2 represent typical results at this position in the control horses. M2' and Id2' represent the results from laminitic horse 2. Average molecular weights $(\mathrm{kDa})$ are given for some of the polypeptides.

\section{Results}

The bio- and immunohistochemistry results were compared with those in 8 normal horses reported on previously (Wattle 1998), which served as controls in the present study.

\section{Biochemistry}

The number of cytokeratins separated by 1-D and 2-D gel electrophoresis was the same in corresponding samples among control and lam-

Figures 4-8: Illustrations of typical results from the immunohistochemical analysis of normal equine hooves and hooves from horses with acute laminitis, using monoclonal antibodies (Mab). A positive reaction yields a brown product. The complete staining results are presented in Table $3 \mathrm{a}$ and $3 \mathrm{~b}$. Common symbols: white arrow indicates stratum basale; open white arrow indicates stratum spinosum or suprabasal cells; black arrow indicates cornified (or uncornified) primary epidermal laminae (PEL) and points towards the inner parts of the hoof. Open black arrow indicates the corium, including primary dermal laminae (PDL) and secondary dermal laminae (SDL). SEL $=$ secondary epidermal laminae.
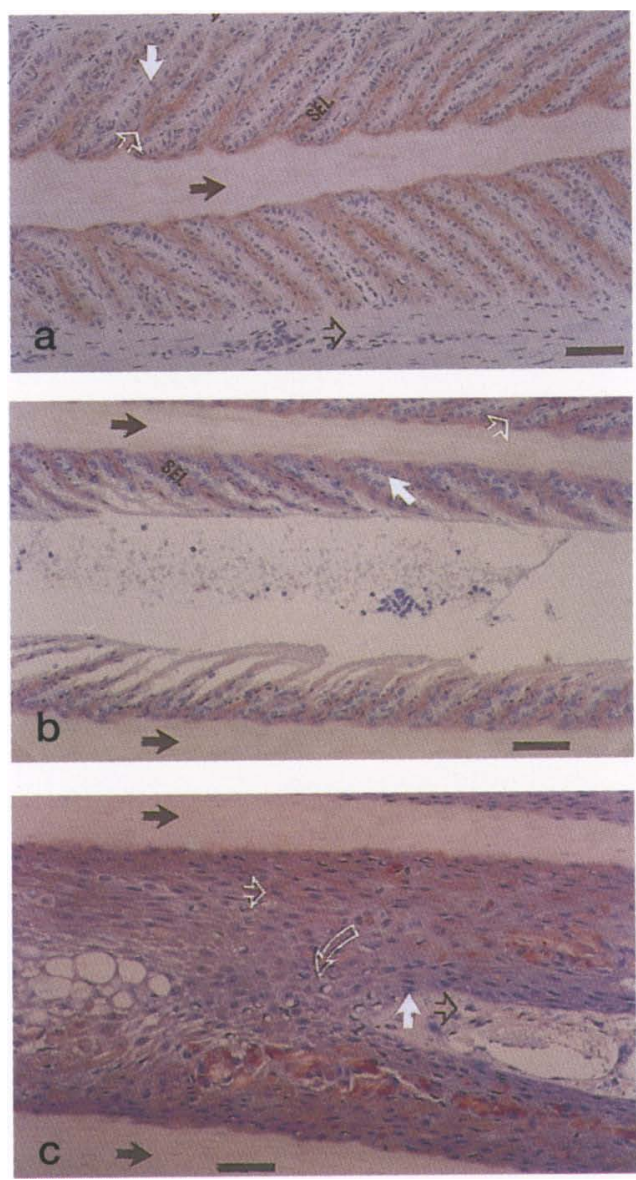

Figure 4 (a-c): Cross-sections from the stratum internum. A 5/6 Mab.

(a) Control horse, Id level. Reaction with suprabasal cells and possible reaction with basal cells (bar $=$ $63 \mu \mathrm{m})$.

(b) Horse 2, Id level. Absence of PDL, SDL and basal cells along the deep parts of the SEL following downward displacement of the third phalanx with complete dissociation of the dermal and epidermal laminae. Reaction with suprabasal cells (bar $=63 \mu \mathrm{m}$ ).

(c) Horse 3, Id level. Outermost part of the laminar layer. Hyperplasia and cellular oedema are seen among the epidermal cells (the oedema is most distinct below and to the left of the curved open white arrow). No SEL are present. There is a reaction with suprabasal cells but only a weak reaction in the first cell layers (bar $=63 \mu \mathrm{m})$. 

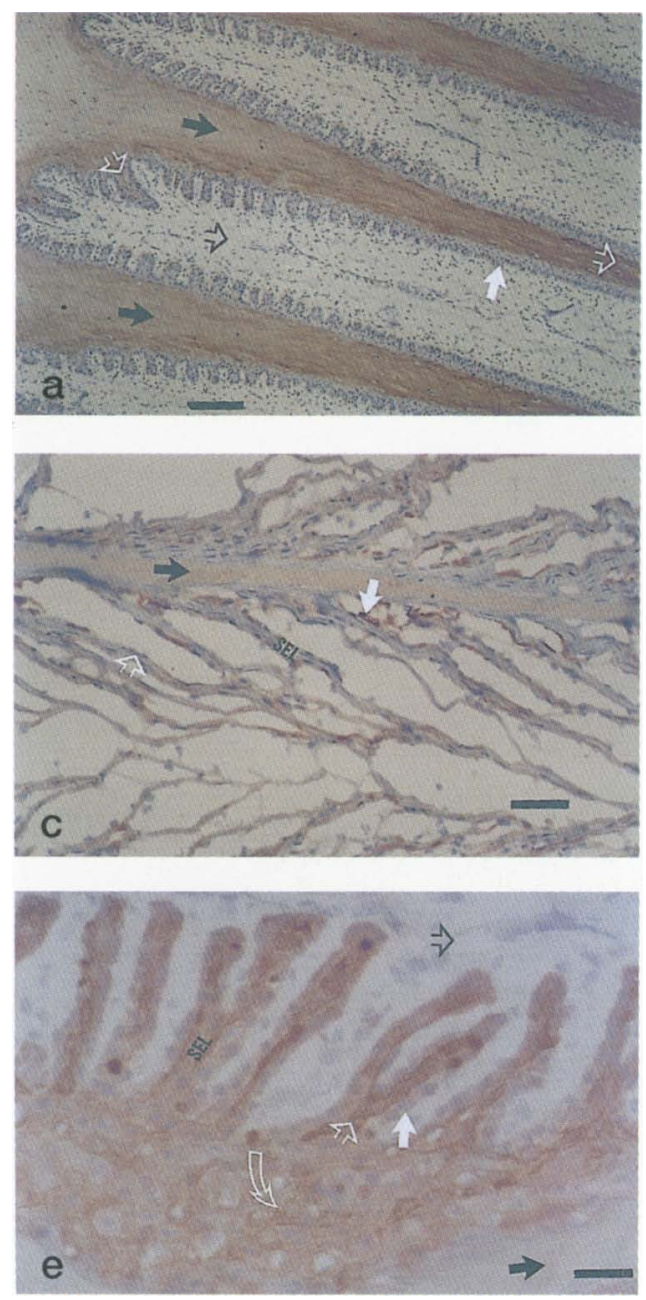

initic horses, as were the corresponding molecular weights and isoelectric points (Figs. 2a and b, Fig. 3 and Table 2). Likewise, the relative amount of the individual cytokeratins (CKs) was approximately the same in corresponding samples

\section{Morphology}

Histological examination of the control material stained with Mayers H\&E revealed no path-
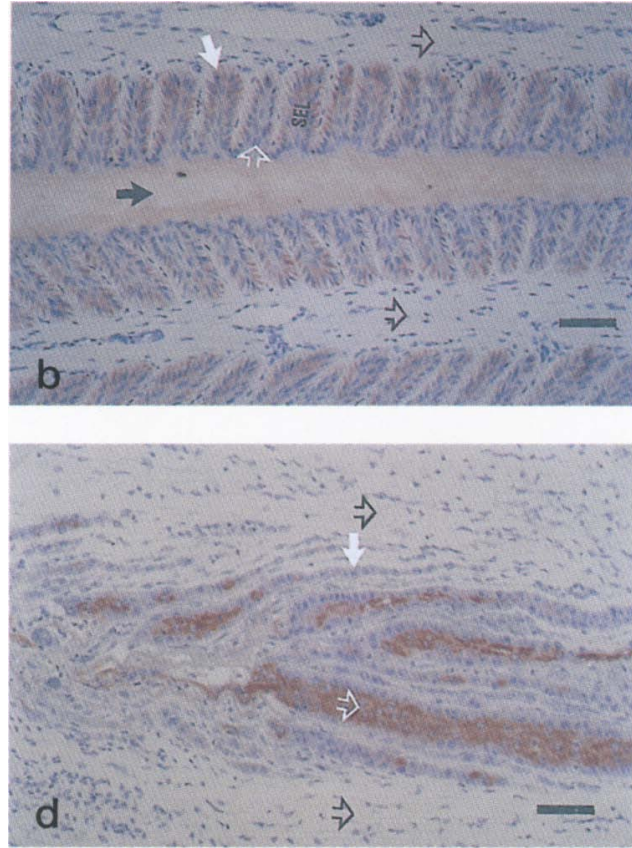

Figure 5 (a-e): Cross-sections from the stratum internum. CK 8.12 Mab.

(a) Control horse, Ip level. Outermost and central part of the laminar layer. Small SEL can be seen along the left half of the PEL. Reaction with cells in PEL. In larger SEL at this level, the suprabasal cells show a reaction with the Mab $(b a r=125$ $\mu \mathrm{m})$.

(b) Control horse, Id level. Reaction with the basal cell layer and possible reaction with suprabasal cells in the deepest part of the SEL (bar $=63 \mu \mathrm{m}$ ).

(c) Horse 2, Id level. Absence of dermal tissue (for position compare Fig. 7d). The SEL are partially stretched out into thin cords. The Mab reacts only with remaining parts of damaged basal cells along the SEL (white arrow) (bar $=63 \mu \mathrm{m}$ ).

(d) Horse 2, same section as in (c) but in the innermost part of the displaced laminar layer (for position compare Fig. 7d). SEL basal cells that were displaced together with the dermal laminae. Strongly positive reaction only in newly formed suprabasal cells $(\mathrm{bar}=63 \mu \mathrm{m})$.

(e) Horse 1, Id level, cryostat section. The SEL are slightly stretched out. There is an increased number of cells along PEL (curved white arrow). There is marked staining of suprabasal cells but also weak staining of basal cells ( $\mathrm{bar}=63 \mu \mathrm{m}$ ). 

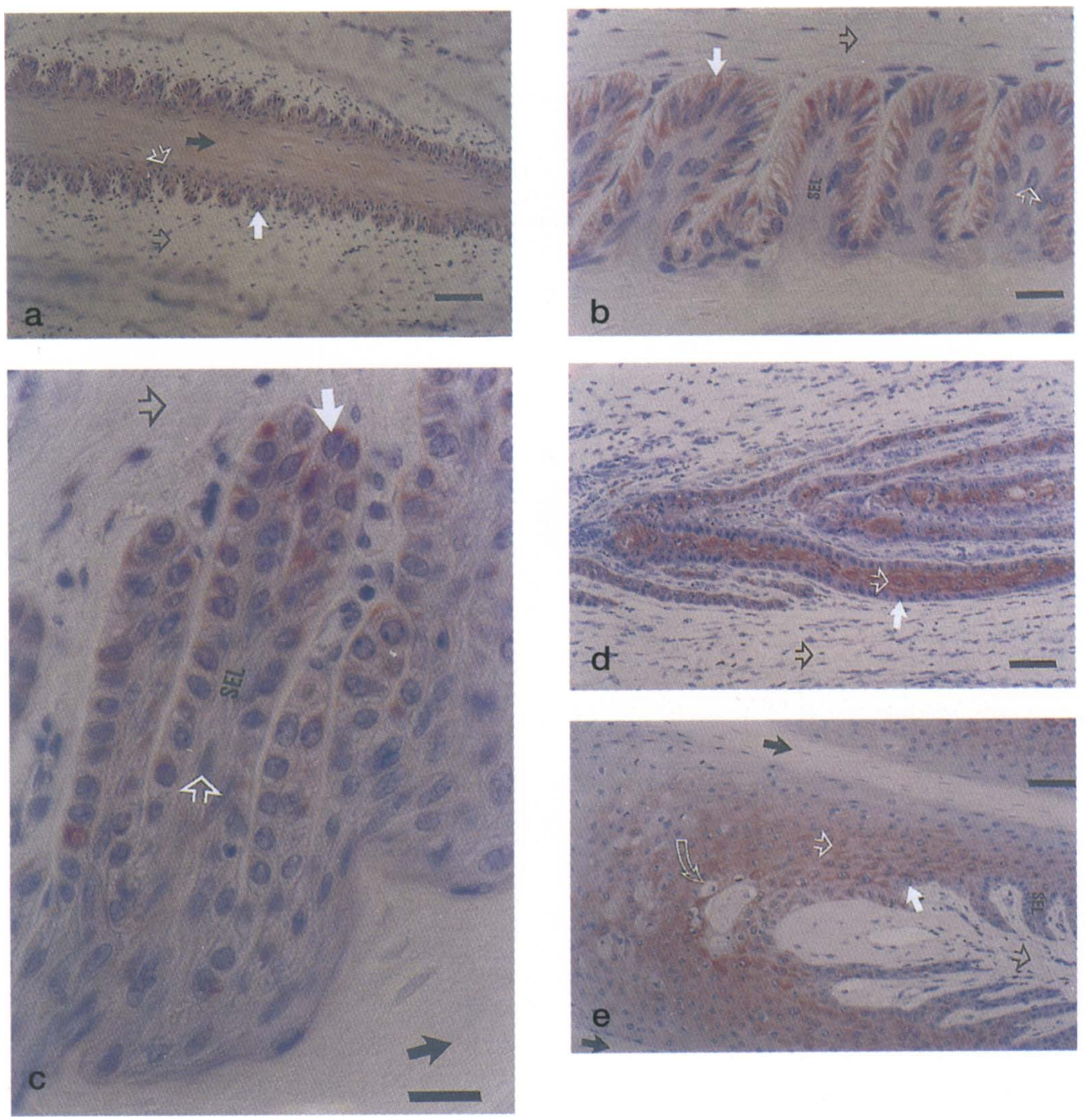

Figure 6 (a-e): Cross-sections from the stratum internum. AE1/AE3 Mab.

(a) Control horse, Ip level. Central part of the laminar layer. Positive reaction with basal and suprabasal cells (bar $=63 \mu \mathrm{m}$ ).

(b) Control horse, Id level. Positive reaction with basal cells (bar $=20 \mu \mathrm{m})$.

(c) Horse 1, Id level. Relatively small morphological changes such as slightly stretched SEL with round appearance of basal cell nuclei; compare (b). Positive reaction with basal cells (bar $=20 \mu \mathrm{m}$ ).

(d) Horse 2, Id level. Innermost part of the displaced laminar layer. Positive reaction with basal and suprabasal cells (bar $=63 \mu \mathrm{m})$.

(e) Horse 1, Ip level. Outermost part of the laminar layer. Hyperplasia and cellular oedema are observed among the epidermal cells (curved open white arrow). Positive reaction in suprabasal cells except for the 2-3 cell layers adjacent to the cornified PEL. These latter 2-3 cell layers correspond to the normal number of suprabasal cells in this position at the Ip level (bar $=63 \mu \mathrm{m})$. 

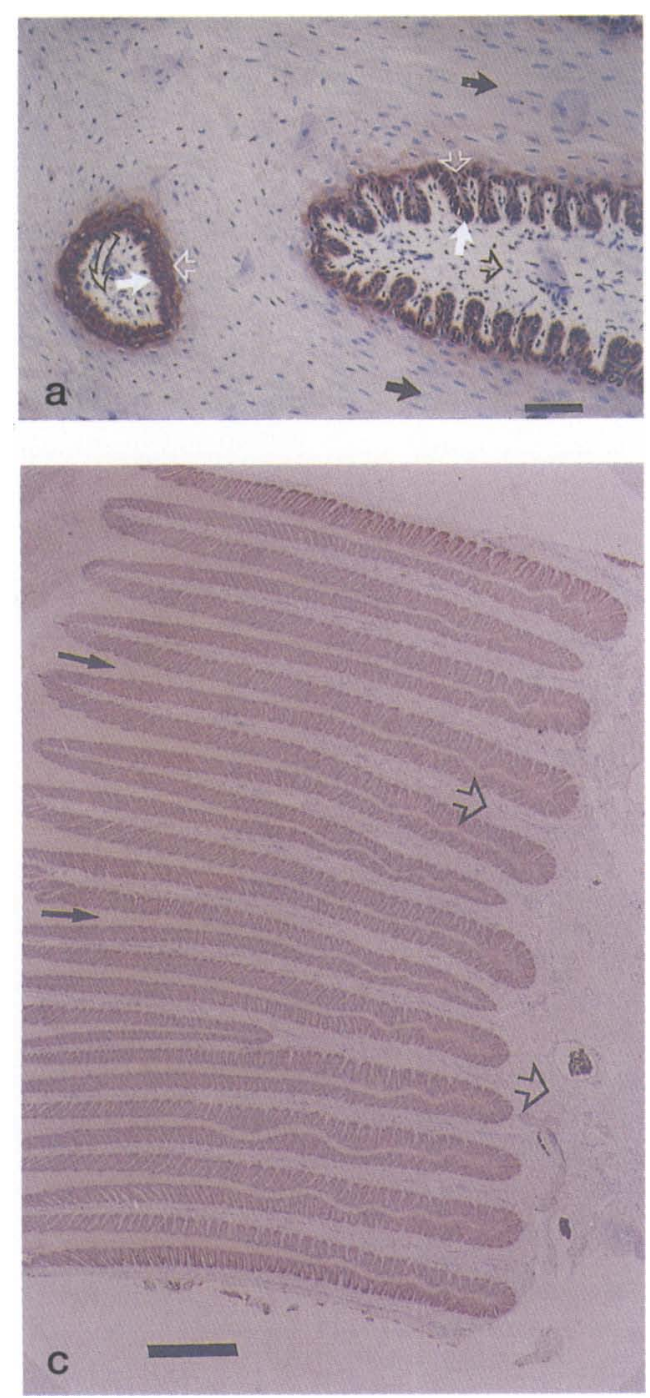

ological changes among the epidermal cells. Differences in the morphology of the laminar layer between laminitic and normal horses (independent of the Mab used) are illustrated in Figs. 4, 5, 6 and 7. Since a complete account of the histopathological findings is not within the scope of the present study, the morphological findings in the laminitic horses are summarized
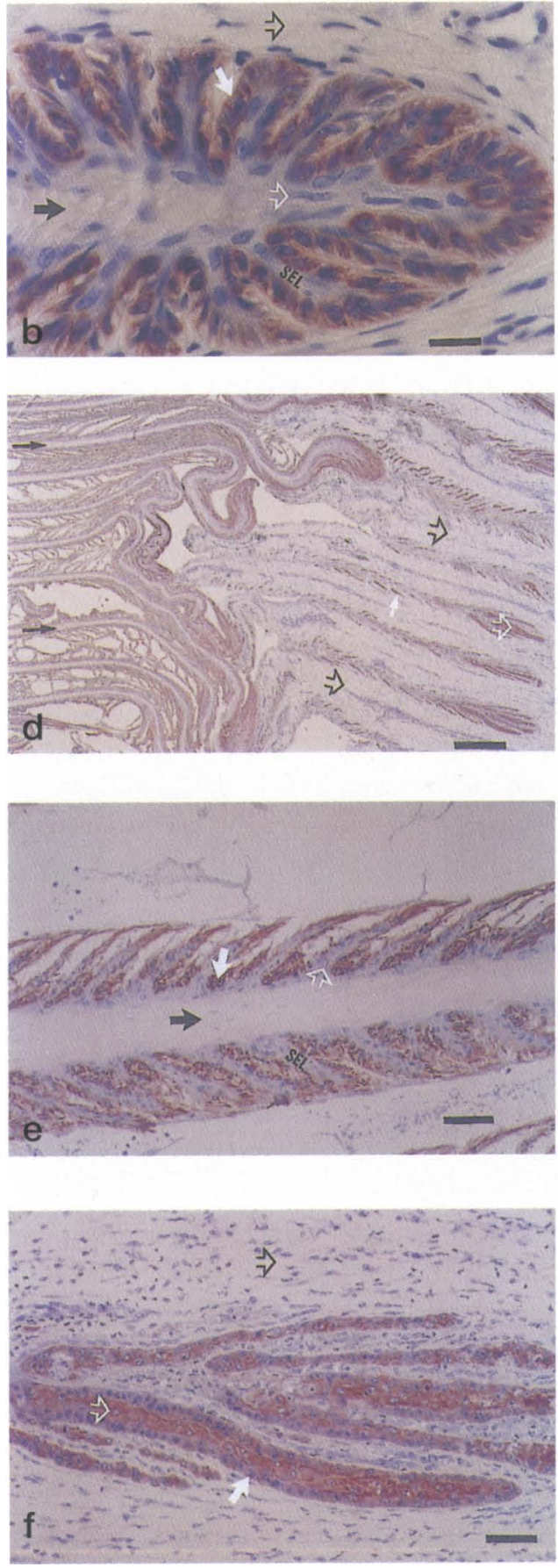
below to simplify the understanding of the immunohistochemical differences between hooves. In the laminitic horses, all hooves sampled displayed varying degrees of histopathological changes in the laminar layer, such as elongation of the primary epidermal laminae (PEL) and SEL (Fig. 6c), hyperplasia (cell proliferation) (Figs. 4c, 5e and 6e), oedema (Figs. $4 \mathrm{c}$ and $6 \mathrm{e}$ ), rounding of the basal cell nuclei (Fig. 6c), and necrotic cells. In horse 2, in which the laminitis had a very rapid course, almost complete dissociation between the dermal and epidermal laminae was seen in one hoof (Fig. 7d, compare with Fig. 7c). Hyperplasia of the suprabasal cell layer was most typically found in the outermost (Figs. 4c and 6e) and innermost (Figs. 5d, 6d and 7f) parts of the laminar layer, with the exception of the above mentioned areas with complete dissociation, in which there was no hyperplasia of the suprabasal cell layer. Judged from the observed number of suprabasal cells and mitotic figures, the rate of keratinocyte proliferation seemed to differ most from that in the control horses at the Id level.

Concerning the morphological changes among the hooves of the individual horses, the following are worth mentioning: The laminar layer in samples from horse 1 showed a scale of changes from mild, with a macroscopically normal appearance (right rear hoof), to moderate (right front hoof). In the left front hoof of horse 2 there was almost complete dissociation of the dermal and epidermal laminae, whereas the other 3 hooves displayed slightly less severe changes. The front hoof examined in horse 3 showed severe changes without complete dissociation of the dermal and epidermal laminae. Compared to that in horse 2, the laminar layer in horse 3 was 1.4 times longer in the dorso-palmar direction. In horses 1 and 3, there was an increase in the number of suprabasal cell layers outlining the cornified primary epidermal laminae (Figs. 4c, 5e and 6e). In horses 1 and 3 and in the rear hooves of horse 2 , the elongation of the laminar layer was slightly more marked at the Id level than at the Ip level.

The matrix of the stratum medium showed only mild morphological changes, such as a change in the direction of the dermal papillae. Numerous cells in mitosis were seen (Fig. 8b).

\section{Immunohistochemistry}

The staining results in the stratum medium and stratum internum of the laminitic and control horses are summarized in Tables $3 \mathrm{a}$ and $\mathrm{b}$ and

$\leftarrow$ Figure 7 (a-f): Cross-sections from the stratum internum. CK 14 Mab.

(a) Control horse, Ip level. Outermost part of the laminar layer. Curved open black arrow indicates a dermal papilla of the coronary corium. There is a strong positive reaction of basal and spinosal cells of the papilla of the stratum medium and basal cells of the stratum internum. Suprabasal cells of small SEL show a reaction but less distinct (bar $=63 \mu \mathrm{m})$.

(b) Control horse, Id level. Innermost part of the laminar layer. There is a positive reaction with basal cells (bar $=20 \mu \mathrm{m}$ ).

(c) Control horse. General view of the laminar layer at the Id level. Normal appearance of laminar layer. There is a positive reaction with basal cells ( $\mathrm{bar}=500 \mu \mathrm{m}$ ).

(d) Horse 2, Id level. Complete dissociation of the dermal and the epidermal laminae. On the right-hand side of the figure, dermal laminae are displaced together with a number of basal cells towards the inner parts of the hoof. There is a positive reaction in basal and suprabasal cells in the inner region (bar $=500 \mu \mathrm{m})$.

(e) Horse 2, Id level. The SEL are not as stretched out in this section as in the section of Fig. 5c. Basal cells and remnants of basal cells along the SEL show a positive reaction $(\mathrm{bar}=63 \mu \mathrm{m})$.

(f) Horse 2, higher magnification of the inner part of the laminar layer (i.e. lower right-hand part of Fig. 7d). There is a positive reaction with basal and suprabasal cells $(\mathrm{bar}=63 \mu \mathrm{m})$. 

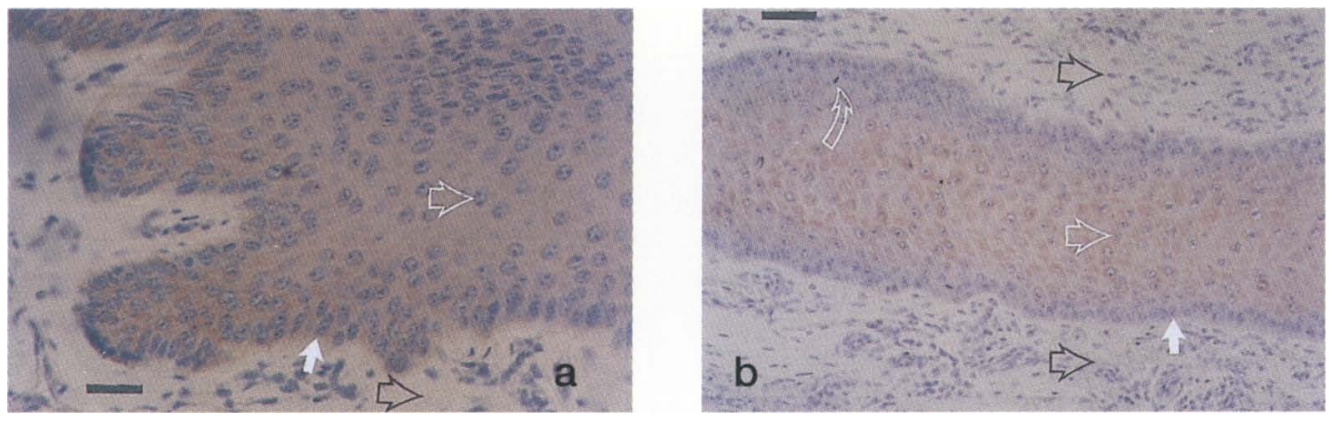

Figure 8 (a-b): Sagittal sections from the most proximal part of the matrix of the stratum medium of the hoof wall. Open white arrow indicates spinosal cells and direction of growth. Open black arrow indicates corium papillae. AE1/AE3 Mab.

(a) Control horse. Moderate positive reaction with basal cells and early spinosal cells (bar $=31.5 \mu \mathrm{m}$ ).

(b) Horse 2 . There is a slightly positive reaction with basal cells and moderate reaction with spinosal cells. Note the mitosis suprabasally (curved white arrow) $(\mathrm{bar}=63 \mu \mathrm{m})$.

illustrated in Figs. 4, 5, 6, 7 and 8. The results presented in the table are average values for all horses since there were only minor differences in the intensity of the reaction between sections within the groups.

In the laminar layer of the laminitic horses, the most obvious change in the reaction with the Mabs was observed in the samples from the Id position (that is, the region where morphologically the rate of proliferation seemed to differ most from the control horses). In the laminar layer at this level, the reaction with CK 8.12 shifted from the basal cell layer in the control horses (Fig. 5b) to the suprabasal cell layers in the laminitic horses (Fig. 5d), giving a reaction pattern very similar to that at the Ip level in the control horses (Fig. 5a, Table 3a), also in SEL with only minor morphological changes. A stronger reaction in the suprabasal cells at the Id level, compared to the normal horses (Fig. 6b), was also observed with the AE1/AE3 Mab (Fig. 6d, Table 3a); however, in parts of the epidermal laminae at the Id level in horse 1, which showed relatively slight morphological changes (Fig. 6c), the reaction with the AE1/AE3 Mab resembled the reaction at the same position in the control horses (Fig. 6b). Likewise, the reaction with the CK 14 Mab increased among the suprabasal cells at the Id level in the laminitic horses, but only in parts where marked proliferation was observed (compare Figs. 7f and b).

In samples from horse 2, with complete dissociation of the dermal and epidermal laminae at the level of sample Id, the CK 8.12, AE1/AE3, and CK 14 Mabs did not react with the suprabasal cells of SEL that were left along the primary epidermal laminae (Figs. 5c and 7e). On the other hand, the suprabasal cells in the inner part, where they were surrounded by basal cells and corium, reacted positively with these Mabs (Figs. 5d, 6d and 7f).

In the matrix of the stratum medium, there was no marked difference in the staining of the spinosal cells between the 2 groups, but with the AE1/AE3 Mab the staining reaction was decreased among the basal cells in the laminitic horses (Table 3b, Figs. 8a and b).

\section{Discussion}

The criteria applied for inclusion of a horse with acute laminitic horse in this study meant that the number of horses was limited. How- 
Table 3a. Result of immunohistochemical staining of sections from the stratum internum of the hoof wall.

\begin{tabular}{|c|c|c|c|c|c|c|c|}
\hline $\begin{array}{l}\text { Str. internum (Ip) } \\
\text { Control horses }\end{array}$ & A $5 / 6$ & CK 8.12 & CK 8.60 & CK 10 & AE1/AE3 & CK 14 & TBS \\
\hline Str. basale & $(+)$ & - & $(+)$ & - & ++ & ++ & - \\
\hline Str. suprabasale & +++ & $++a$ & + & - & $++^{b}$ & + & - \\
\hline Str. corneum & - & + & + & - & - & - & - \\
\hline \multicolumn{8}{|l|}{ Laminitic horses } \\
\hline Str. basale & $(+)$ & - & - & - & ++ & +++ & - \\
\hline Str. suprabasale & ++ & $+++^{\mathrm{a}}$ & + & - & $++^{b}$ & ++ & - \\
\hline Str. corneum & - & + & $(+)$ & - & - & - & - \\
\hline \multicolumn{8}{|l|}{ Str. internum(Id) } \\
\hline Control horses & A $5 / 6$ & CK 8.12 & CK 8.60 & CK 10 & AE1/AE3 & CK 14 & TBS \\
\hline Str. basale & $(+)$ & t+ & $(+)$ & - & ++ & ++ & - \\
\hline Str. suprabasale & ++ & $(+)$ & + & - & - & $(+)$ & - \\
\hline Str. corneum & - & + & $(+)$ & - & - & - & - \\
\hline \multicolumn{8}{|l|}{ Laminitic horses } \\
\hline Str. basale & $(+)$ & $(+) \rightarrow+c$ & - & - & + & +++ & - \\
\hline Str. suprabasale & ++ & +++ & + & - & $(+)^{d} \rightarrow++$ & $(+)^{\mathrm{d}} \rightarrow+++^{\mathrm{e}}$ & - \\
\hline Str. corneum & - & $(+)$ & $(+)$ & - & - & - & - \\
\hline
\end{tabular}

Table $3 \mathrm{~b}$. Result of immunohistochemical staining of sections from the matrix of the stratum medium of the hoof wall.

Str. medium (EM

and $\mathrm{M}$ )

A $5 / 6$

CK 8.12 CK 8.60

CK 10

AE1/AE3

CK 14

TBS

Control horses

\begin{tabular}{|c|c|c|c|c|c|c|c|}
\hline Str. basale & + & - & - & - & ++ & ++ & - \\
\hline Str. spinosum & + & +++ & - & - & ++ & ++ & \\
\hline Str. spinosum & - & ++ & $-\rightarrow(+)^{f}$ & - & + & + & - \\
\hline Str. corneum & - & - & - & - & - & - & - \\
\hline \multicolumn{8}{|c|}{ Laminitic horses } \\
\hline Str. basale & + & - & - & - & $+\rightarrow++g$ & +++ & - \\
\hline Str. spinosum & $+\mathrm{g} \rightarrow++$ & +++ & - & - & ++ & ++ & - \\
\hline Str. spinosum & $(+)$ & ++ & $(+)$ & - & + & + & - \\
\hline Str. corneum & - & - & $(+)$ & - & - & - & - \\
\hline
\end{tabular}

Comments on Table $3 a$ and $b$.

- Negative; $(+)$ possible staining, i.e. slight and inhomogeneous; + slight and homogeneous; ++ moderately; and +++ strongly positive. TBS $=$ Tris-buffered saline, used as a negative control. In Table $3 b$, the first line of stratum spinosum stands for the first spinous cell layers

(above the basal cells), and the second line stands for the rest of the Stratum spinosum.

a The first suprabasal cell layer does not show a positive reaction in parts of the laminae where no or very small secondary laminae can be seen (Fig. 5a).

b There was no staining in the 1-3 cell layers of suprabasal cells next to the stratum corneum in the PEL (for example, see Fig. 6e).

c There was weak but distinct staining of the basal cells in sections, while the basal cells were only possibly stained in paraffin sections.

d In horse 1, the suprabasal cells did not stain in SEL with relatively small morphological changes (Fig. 6c).

e Suprabasal cells in areas with hyperplasia.

f Single cells at the border of the stratum corneum.

g Cells outlining the corium papillae (i.e., at the most distal parts of the samples). 
ever, morphological differences between hooves, ranging from areas with slightly elongated secondary epidermal laminae to areas with complete dissociation of the dermal and epidermal laminae, and the original level of the sample, i.e. proximal vs distal, were considered more important for the immunohistochemical results than differences between horses, and the number of horses.

Objections might be raised against the fact that the laminitic horses were all mares and were older than the control horses, but since the biochemical findings indicated the same set of cytokeratins in the 2 groups of horses, it is reasonable to suggest that the age and sex of the laminitic horses in the present study did not affect the results.

A change in the tissue distribution of the cytokeratins and an increased rate of keratinocyte proliferation were observed at the Id level of the stratum internum in the laminitic horses of this study. In the normal horse, the rate of proliferation is higher at the Ip than at the Id level (Budras et al. 1989, Wattle 1998), but the basal cells at the Id level seem to have a dormant proliferative capacity (Roberts et al. 1980). It appears from the present findings that this capacity to proliferate implies that no new types of cytokeratins are produced when the tissue reacts with increased proliferation (Table 2); however, the keratinocytes express the cytokeratins in a different cell layer from what is normal at the Id level of the laminar layer (Table 3a). Several parts of the sections from the Id level in the laminitic horses showed a reaction with the CK 8.12, AE1/AE3, and CK 14 Mabs, resembling the samples from the Ip rather than from the Id level in the control horses (Table $3 a)$. This is probably due to the increased rate of proliferation at the Id level seen among the laminitic horses. This may be compared with wound healing in human skin, where cytokeratins that are normally restricted to the basal layer appear suprabasally at the wound margin. In wound healing, however, the keratinocytes also start to induce new short-filament keratins (Martin 1997). In skin the mechanical properties of the tissue seem to change if there is a disturbance in the expression of cytokeratins in a cell layer, for example when other cytokeratins are synthesised (Fuchs 1995, Fuchs \& Cleveland 1998).

The decreased reaction with the AE1/AE3 Mab in the basal cells of the matrix of the stratum medium of the hoof wall is also probably the result of increased proliferation, since numerous cells in mitosis were observed.

In horse 1 the CK 8.12 Mab differed from the AE1/AE3 and CK 14 Mabs in that it reacted with suprabasal cells at the Id level in all SEL examined, that is, including SEL showing relatively slight morphological changes. If this distinct reaction with CK 8.12 (at the Id level) precedes the early morphological changes in the laminar layer (such as elongation of the SEL), it may indicate a change in the cytoskeleton of both the basal and suprabasal cells that might decrease the tensile strength of these cells. However, in horse 1, there were distinct morphological changes in other parts of the laminar layer within the same hooves. The possibility cannot be excluded that the laminitic process in these parts also affects the expression of cytokeratins by the keratinocytes in parts of the laminar layer with relatively small morphological changes. In addition, in horse 2 , where the downward displacement of the third phalanx had a very rapid course, the CK $8.12 \mathrm{Mab}$ did not stain the suprabasal cells of the SEL that were left along the PEL (Fig. 5c). The absence of a reaction with the CK 8.12 Mab amongst the suprabasal cells in this case suggests that a change in cytokeratin expression does not precede the elongation of the SEL. Note (Fig. 5c) that the majority of the basal cells in these areas were all seriously damaged. It may be men- 
tioned that the rest of the basal cells were left on the dermal laminae (the disruption seemed to be located mainly in the basal cell layer of the SEL), and in this environment the CK 8.12 Mab reacted with the suprabasal cells (Fig. 5d). Hence it is reasonable to believe that the suprabasal cells need the influence of corium and/or basal cells before they can alter their content of cytokeratins. To completely answer the question as to whether the cytokeratins reacting with the CK $8.12 \mathrm{Mab}$ at the Id level change before the SEL becomes elongated, the cytokeratins have to be studied during the developmental phase of laminitis. It is also possible that they are only an earlier marker for increased proliferation compared to the cytokeratins reacting with the AE1/AE3 and CK 14 Mabs.

In contrast to the other Mabs, the CK 8.12 Mab showed a difference in the reaction pattern between the paraffin and cryostat sections (Table 3a). Compared to corresponding paraffin sections, where there was only a possible reaction, there was a weak but distinct reaction of CK 8.12 Mab with basal cells at the $I d$ level in cryostat sections from the laminitic horses (Fig. 5e). As the amount of the brown product indicating a positive reaction depends on the amount of the individual cytokeratins and the specificity of the Mabs for the polypeptides, the difference in staining of the basal cells between the cryostat and paraffin sections might be the result of a weak reaction between the CK 8.12 Mab and the epitope and/or of insufficient unmasking of the antigen in the paraffin sections. Regarding the expression of certain cytokeratins in the stratum internum, the following postulations may be made. By comparing the observed specificity of the Mabs (Table 1) with the proteins biochemically classified as cytokeratins (Table 2), the biochemical results of Wattle (1998), and the immunohistochemical results in the control and laminitic horses (Ta- ble $3 \mathrm{a}$ and $\mathrm{b}$ ), the following seems reasonable: The acidic 52.0, 49.6, and 47.2 kDa cytokeratins are most probably so-called hard cytokeratins (Wattle 1998). The reason for the shift in the CK 8.12 Mab reaction at the Id level from basal cells in the control horses to suprabasal cells in the laminitic horses, including SEL with relatively small morphological changes, can probably be found among these cytokeratins. This assumption is based on the facts that the other cytokeratins reacting with the $\mathrm{CK}$ 8.12 Mab (i.e. the acidic 59.5, 56.5, and 55.3 $\mathrm{kDa}$ cytokeratins) also react with the AE1/AE3 $\mathrm{Mab}$ and that the $56.5 \mathrm{kDa} \mathrm{CK}$ also reacts very specifically with the CK $14 \mathrm{Mab}$, which did not react with suprabasal cells in SEL with relatively slight morphological changes. Further, in view of the specificity of the CK $8.60 \mathrm{Mab}$ towards the 59.5 and $55.3 \mathrm{kDa}$ cytokeratins, the weak reaction of the CK $8.12 \mathrm{Mab}$ with the basal cells at the Id level in the cryostat sections from the laminitic horses is most likely caused by the $56.5 \mathrm{kDa}$ cytokeratins. The fact that the reactions with the CK 8.60 and A5/6 Mabs did not differ between the 2 groups of horses indicates that the expression of the $59.5 \mathrm{kDa}$ (basic and acidic) and 55.3 cytokeratins does not change in acute laminitis. The reaction with the AE1/AE3 and CK14 Mabs in suprabasal cells in areas with increased proliferation is most likely attributable to the $56.5 \mathrm{kDa}$ cytokeratins, and in the case of the AE1/AE3 Mab, probably also to the basic $65 \mathrm{kDa}$ cytokeratins. The 62.2 $\mathrm{kDa}$ cytokeratin might also play a role in this change in reaction with the AE1/AE3 Mab.

The 56.5 (acidic) and 65 (basic) kDa cytokeratins in the horse most probably correspond to the human cytokeratins K14 (acidic) and K5 (basic), respectively, since they are expressed in the basal cells of normal epidermis. In humans, the K14 and K5 mRNAs seem to be restricted to cells that maintain their proliferative capacity (i.e. basal cells in normal epidermis) (Byrne 
et al. 1994). If this restriction to cells with a proliferative capacity is also true for the equine 56.5 and $65 \mathrm{kDa}$ cytokeratins, this will mean that the suprabasal cells maintain their proliferative capacity in areas with increased proliferation, since they express these cytokeratins in these areas. This might explain why the epidermal cells of the laminar layer are able to fill the space left by the displaced dermal laminae in a matter of days (personal observation).

The results of this study do not contradict Obel's hypothesis that the primary disturbances in laminitis delay the differentiation of the epithelial cells and thereby alter the fibrillar structures within the keratinocytes, but it appears that this primary disturbance does not affect the cytokeratins. However, during the normal differentiation of keratinocytes in hair, the space between the filaments is filled by numerous smaller so-called keratin associated proteins (KAPs) of the cysteine-rich and glycine/tyrosine-rich protein families (Powell \& Rogers 1997). These proteins might be a part of the onychogenic acidophilic fibrillar structures mentioned by Obel (1948). This hypothesis might be supported by the findings of Larsson et al. (1956). Using autoradiography, they observed a disturbed incorporation of cystine in 2 horses with experimentally induced alimentary laminitis. The influence of the laminitis-triggering agent on epidermal proteins other than cytokeratins (such as KAPs) was not included in the present work; however, the silver staining of proteins in electrophoretic gels indicated a change in production of some proteins not belonging to the cytokeratin family. A detailed analysis of the KAPs and the proteins involved in the desmosomal/hemidesmosomal plaques during normal hoof growth and during development of laminitis should lead to a better understanding of their role in the pathogenesis of this disease.

In conclusion, there is no change in the set of cytokeratins in the living epidermal cell of the weight-bearing parts of the equine hoof wall in an acute attack of laminitis, but there is a change in the tissue distribution of cytokeratins in areas with markedly increased keratinocyte proliferation. However, since the development of laminitis was not studied, no conclusion could be drawn as to whether this change was primary or was caused by the initiation of the local tissue-repairing process.

\section{Acknowledgements}

This work was supported by the Gerhard Forssell Foundation.

\section{References}

Baden HP, Kvedar JC: The nail. In: Goldmith LA (Ed): Physiology, Biochemistry, and Molecular Biology of the Skin, 2nd ed. Oxford University Press, 1991, pp 697-711.

Budras KD, Hullinger RL, Sack WO: Light and electron microscopy of keratinization in the laminar epidermis of the equine hoof with reference to laminitis. Am. J. Vet. Res. 1989, 50, 1150-1160.

Byrne C, Tainsky M, Fuchs E: Programming gene expression in developing epidermis. Development 1994, 120, 2369-2383.

Cattoretti G, Pileri S, Parravincini C, Beckers MHG, Poggi S, Bifulco C, Key G, D'Amato L, Sabattini E, Feudale E, Reynold F, Gerdes J, Rilke F: Antigen unmasking on formalin-fixed, paraffin-embedded tissue sections. J. Pathol. 1993, 171, 8398

Coffman JR, Johnson JH, Guffy MM, Finocchio EJ: Hoof circulation in equine laminitis. J. Am. Vet. Med. Assoc. 1970, 156, 76-83.

Ekfalck A: Studies on the morphology and biochemistry of the epidermal tissue of the equine and the bovine hoof with special reference to laminitis. Dissertation, Uppsala. 1991.

Fuchs E: Keratins and the skin. Annu. Rev. Cell. Dev. Biol. 1995, 11, 123-153.

Fuchs E: Of mice and men: Genetic disorders of the cytoskeleton. Mol. Biol. Cell. 1997, 8, 189-203

Fuchs E, Cleveland DW: A structural scaffolding of intermediate filaments in health and disease. Science 1998, 279, 514-519.

Hazelbag HM. van de Broek LJ. van Dorst EB. Offerhaus GJ. Fleuren GJ. Hogendoorn PC: Immu- 
nostaining of chain-specific keratins on formalinfixed, paraffin-embedded tissues: A comparison of various antigen retrieval systems using microwave heating and proteolytic pre-treatments. J. Histochem. Cytochem. 1995, 43, 429-437.

Hood DM: The pathophysiology of developmental and acute laminitis. In: Turner S, Hood DM (Eds): The Veterinary Clinics of North America. Equine Practice. W.B. Saunders Company, Philadelphia, 1999, 15, 321-343

$H$ su $S$-M. Raine L. Fanger $H$ : Use of avidin-biotinperoxidase complex $(\mathrm{ABC})$ in immunoperoxidase techniques: A comparison between $\mathrm{ABC}$ and unlabeled antibody (PAP) procedures. J. Histochem. Cytochem. 1981, 29, 577-580.

Johnson PJ. Tyagi SC. Katwa LC. Ganjam VK. Moore LA. Kreeger JM. Messer NT: Activation of extracellular matrix metalloproteinases in equine laminitis. Vet. Rec. 1998, 142, 392-396.

Larsson B. Obel N. Aberg B: On the biochemistry of keratinization in the matrix of the horse's hoof in normal conditions and in laminitis. Nord. Vet. Med. 1956, 8, 761-776.

Linford RL: A radiographic, morphometric, histological, and ultrastructural investigation of lamellar function, abnormality and the associated radiographic findings for sound and footsore thoroughbreds, and horses with experimentally induced traumatic and alimentary laminitis. Dissertation, Davis, California. 1987.

Martin P: Wound healing-aiming for perfect skin regeneration. Science 1997, 276, 75-81.

Obel N: Studies on the histopathology of acute laminitis. Dissertation, Stockholm. 1948.

Pollit CC: Basement membrane pathology: a feature of acute equine laminitis. Equine Vet. J. 1996, 28, 38-46.

Pollitt CC, Daradka M: Equine laminitis basement membrane pathology: loss of type IV collagen, type VII collagen and laminin immunostaining. Equine Vet. J. Suppl. 1998, 26, 139-144.
Powell BC, Rogers $G E$ : The role of keratin proteins and their genes in the growth, structure and properties of hair. EXS 1997; 78, 59-148.

Roberts ED, Ochoa R, Haynes PF: Correlation of dermal-epidermal laminar lesions of equine hoof with various disease conditions. Vet. Pathol. 1980, 17, 656-666.

Wattle $O$ : Cytokeratins of the equine hoof wall, chestnut and skin: bio- and immunohistochemistry. Equine Vet. J. Suppl. 1998, 26, 66-80.

Weiss DJ: Equine laminitis: A review of recent research. Equine Pract. 1997, 19, 16-20.

\section{Sammanfattning \\ Cytokeratiner $i$ hovväggens stratum internum och stratum internum vid akut fång.}

Huvudparten av de levande keratinocyternas cytoskelett utgörs av cytokeratiner som har polymeriserat till intermediärfilament. Syftet med denna studie var att, på hästar med akut fång, beskriva uttryckandet av cytokeratiner i de levande epidermala cellerna i hovväggens viktbärande delar. Nio hovar, från 3 hästar, har provtagits inom 48 timmar från första kliniska symtom på akut fång. Cytokeratinerna i hovväggens strata medium och internum karakteriserades med 1och 2-dimensionell elektrofores och cytokeratinernas vävnadsdistribution studerades med immunohistokemi. De biokemiska resultaten uppvisade inga skillnader mellan de akuta fånghästarna och de 8 kontrollhästarna, däremot indikerade de immunohistokemiska resultaten en skillnad mellan de 2 grupperna $\mathrm{i}$ cytokeratinernas vävnadsdistribution $\mathrm{i}$ följande cellager: 1) basalceller i matrix till stratum medium 2) basal- och suprabasalceller i stratum internum, i nivå med hovväggens mitt. Det var inte möjligt att avgöra om skillnaderna i cytokeratinernas vävnadsdistribution var primära eller om de var sekundära till följd av en lokal vävnadsregeneration.

(Received February 23, 2000; accepted August 23, 2000).

Reprints may be obtained from: O. Wattle, Department of Large Animal Clinical Sciences, Faculty of Veterinary Medicine, Swedish University of Agricultural Sciences, Box 7018, S-750 07 Uppsala, Sweden. E-mail: ove.wattle@kirmed.slu.se, tel: +46186713 86, fax: +4618672919. 